\title{
Ideophones and the Aesthetics of Everyday Language in a West-African Society
}

Mark Dingemanse is a post-doctoral researcher at the Max

Planck Institute for

Psycholinguistics. His research interests include the study of meaning as it emerges in situated interaction, the relation between everyday language and verbal art, and the interplay of language, culture, and cognition. mark.dingemanse@mpi.nl

\section{Mark Dingemanse}

ABSTRACT This article explores language, culture, and the perceptual world as reflected in a particular linguistic device: ideophones, marked words that depict sensory imagery. Data from a range of elicitation tasks shows that ideophones are a key resource in talking about sensory perception in Siwu. Their use in everyday conversations underlines their communicative versatility while at the same time showing that people delight in their expressiveness. In ideophones, we have an expressive resource that combines sheer playfulness with extraordinary precision.

KEYWORDS: Siwu, ideophones, language of perception, discourse, aesthetics, semantic categories 


\section{Introduction}

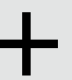

This article explores language, culture, and the perceptual world as reflected in a particular linguistic device: ideophones. Ideophones are marked words that depict sensory imagery such as English hippety-hoppety 'in a hoppingbouncing manner' and shilly-shally 'vacillating,' or Siwu mukumuku

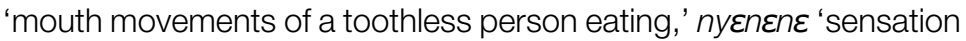
of shivering,' and nyãkãnyãkã 'sensation of grooved texture.' The anthropologist Evans-Pritchard, writing on ideophones in Zande, describes them as follows:

If one had to sum up their character in a short phrase one might say that they are poetry in ordinary language; and one feels that no other sounds would serve the purpose equally well of evoking sensations which compose the meaning, just as one cannot think that any possible line could be substituted for, shall we say, "For ever piping songs for ever new." (EvansPritchard 1962: 145)

It is this idea of poetry in ordinary language that I want to explore by looking at the use of ideophones in Siwu, a language of eastern Ghana. The starting point is data from a range of elicitation tasks that suggest that ideophones, with their highly specific sensory meanings, are a key resource in talking about sensory perception in Siwu. Then I consider their use in discourse, as it is discourse actual instances of use - that "creates, recreates, modifies, and finetunes both culture and language" (Sherzer 1987: 296). In focusing on ideophones in ordinary language, I want to explore possible links between ideophones and everyday aesthetics.

\section{Ideophones as Aesthetic Words}

A late afternoon in a small mountain village in eastern Ghana. A handful of people are idling in the shade of a mango tree in the public forum when a farmer stops by to offer them some fruit for sale. A lively discussion ensues about the quality and freshness of the produce. One person notes that the cassava is nicely smooth (igbèdi sinisinisinisini 'smooth cassava') and that the avocado has the perfect oblong egg-like shape (peà se sodzכ/כככ 'avocado is beautifully oblong'); another suspects that the unripe banana would make one's teeth feel sticky (kànya ame titiritiii 'mouth inside sticky'). The language is Siwu'; the words in bold, ideophones.

Ideophones are conspicuous words in Siwu. They stand out from other words in several ways: they are longer on average than nouns and verbs; they have deviant word structures (featuring, for example, long vowels as in sodzo/כo 'oblong,' or disyllabic reduplicated roots as in sinisini 'smooth'); they are often only loosely integrated in the utterance, if at all; in actual use, they are often emphasized; and finally, they easily undergo expressive prosodic alteration - for 
example, in the above exchange, the final vowel of sodzoloo is greatly lengthened and sinisini is repeated several times.

The effect of all this is that ideophones are quite unlike ordinary words that do their work without attracting much attention themselves; instead, ideophones literally jump out, as words that attract attention qua words, as speech heard in a special way. Set apart from the surrounding linguistic material, they draw us into the scene and invoke images of "being there." The term Lautmahlerei (sound painting), current in early-twentieth-century German writings on ideophones, provides a useful way of understanding this process: like paintings, ideophones invite the listener to savor them as depictions. Their status aparte in the stream of speech may be compared to the frame of a painting; their sound as the canvas at which we are invited to look in such a way that we make believe we are actually experiencing the scene depicted.

Ideophones are not limited to the imitation of sound, the type of mimesis in language that - in the form of onomatopoeia - will be most familiar to speakers of Western languages. In fact, ideophones depict a wide range of sensory imagery across all sensory modalities, from sight, touch, hearing, taste, and smell to kinesthesia, temperature, interoception, and cognitive states (Dingemanse forthcoming a). The scenes evoked by ideophones tend to be rich and imagistic, as in lukuruu 'huge belly,' kpotoro-kpotoro 'tortoise walking,' puruù 'pulp gushing out.' Simple properties on the other hand tend to be expressed in Siwu by stative verbs like $m \dot{\partial}$ 'be big,' I $\varepsilon$ 'be good,' and dzo 'be straight.'

The rich sensory scenes evoked by ideophones bring to mind Evans-Pritchard's succinct characterization of them as "poetry in ordinary language." They are saturated with meaning; in handling them, one feels they are like evocative one-word poems. As Fortune, another student of ideophones, notes,

There is a roundness, a complete shape, not so vividly conveyed by more complex constructions, more formal expressions. [...] Always they try to capture the freshness of an event and express it of themselves with nothing to dull or cloud the evocation. (Fortune 1962: 6)

Their appeal to the senses reveals an aesthetic in von Baumgarten's original sense - a disposition to sense acutely (von Baumgarten 1750; Gregor 1983). In this sense, ideophones are deeply aesthetic.

The second part of Evans-Pritchard's description is equally important: ideophones are poetry in ordinary language. They occur profusely in everyday conversation; as Whitehead noted more than a century ago, "the stories and common speech of the people are full of them" (Whitehead 1899: 18). Though they are also found in genres of verbal art (Noss 2001; Webster 2008; Dingemanse 2009), it is their place in everyday social interaction that concerns us here. This 
points to an everyday aesthetic, to ways of attending to the world that foreground the exact qualities of sensory perception. In this I follow a position previously put forward by Janis Nuckolls (among others) who, in a study of ideophones in Ecuadorian Quechua argues that 'Quechua speakers' use of sound symbolic utterances reveals that they have an overwhelmingly aesthetic interest in their ordinary perceptions" (Nuckolls 1995: 147).

The role of ideophones in ordinary language is more than aesthetic, however. Nuckolls also stresses their communicative import: "sound symbolic words can be important for the exchange of information and the verification of understanding" (1995: 161). This runs counter to earlier conceptions of ideophones, which have often trivialized them as mere dramatic embellishments. As the philologist Max Müller declared, "they are playthings, not the tools of language" (1899). One reason that Müller's words still resonate today is that there have not been many systematic investigations of the meaning and use of ideophones. The next sections provide empirical support for the notion that ideophones reveal an aesthetic interest and are more than stylistic flourish.

\section{Ideophones in the Language of Perception Tasks}

To investigate the role of ideophones in the linguistic coding of perceptual domains, I have used six tasks developed in the MPI Language of Perception project (see Majid and Levinson, this issue; also Majid and Levinson 2007). The six tasks comprised: (1) a texture booklet with ten different textures; (2) a taste kit with the five basic tastes (sweet, sour, bitter, salt, umami); (3) a color booklet consisting of eighty Munsell-validated color chips; (4) a booklet with twenty shapes; (5) a scratch-and-sniff booklet for twelve smells; and (6) a set of ten sound pairs varying in tempo, loudness, and amplitude. For each task, ten to fourteen Siwu speakers from the village of Akpafu-Mempeasem were presented with the stimuli and asked to name them one by one.

The responses to the tasks were classified into four categories: (a) ideophones (e.g. giligili 'circular,' wùrùfùù 'fluffy,' kpinàkpinà 'pitch black'), (b) other abstract perceptual terms (e.g. yuc 'be unripe,'

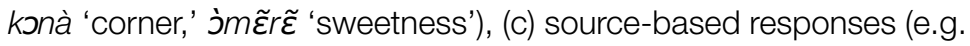
iyata 'leaf,' 'iw̃̃mi 'star,' tsítsere 'sugar'), and (d) evaluative responses (e.g. $/ \varepsilon$ 'be good'). Figure 1 shows the types of responses per task. ${ }^{2}$ The most important thing to notice is that even in this thoroughly unfamiliar and constrained setting - where stylistic flourishes are least called for - speakers turn to ideophones to describe sensory perceptions. Ideophones were used in all six tasks, and they were especially common in the texture, taste, and shape tasks. I take this to mean that ideophones are a key expressive resource in Siwu sensory talk.

In the individual responses to these sensory stimuli we get a feel for the precision that can be attained with ideophones. For example, 

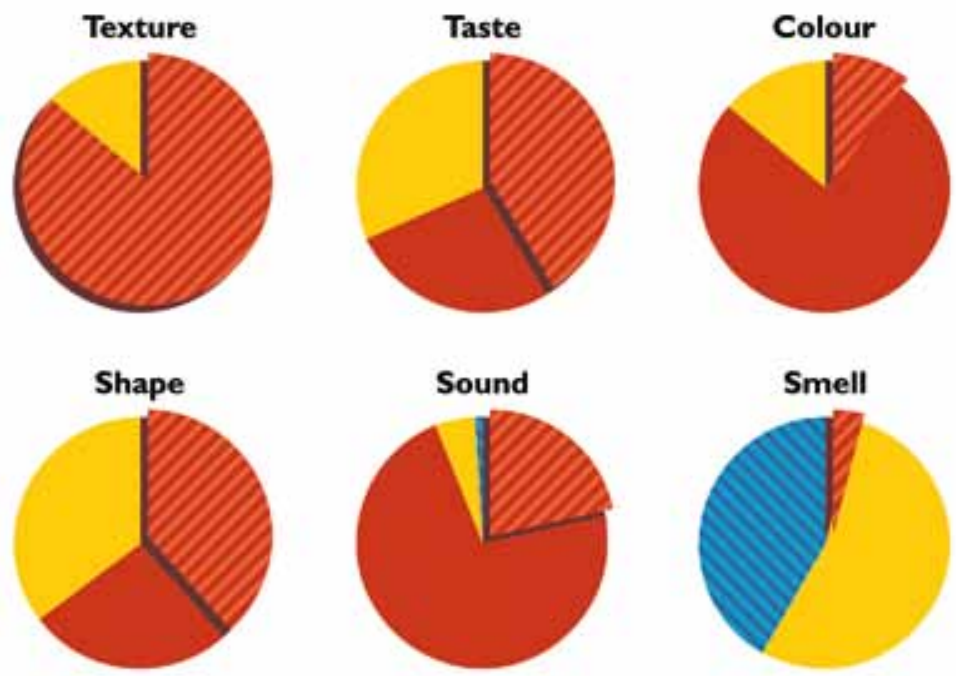

\section{Figure 1}

Types of responses in the Language of Perception data for Siwu.

in the Texture task, in which blindfolded participants explored ten different textures with their fingers, there were twenty-six unique response types, thirteen of which, all ideophones, account for 90 percent of the response tokens. This means that subjects used a number of specific ideophones quite consistently to describe the ten stimuli. Some ideophones with relatively general meanings were used often; for example, wòsòròò 'rough' and pد/دp/smooth' account for about half of the responses, with the best examples (jagged fabric for wòsòròò, plastic sheet and yoga mat for po/دp/د) receiving near-unanimous consistency. Other ideophones used by several

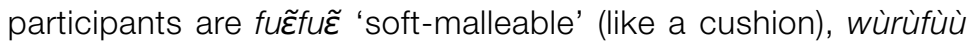

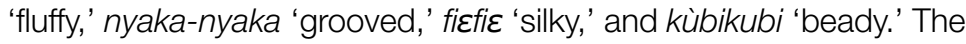
Taste task elicited more source-based descriptions than the Texture task, but here too, ideophones like $m \tilde{\varepsilon} r \tilde{\varepsilon} m \tilde{\varepsilon} r \tilde{\varepsilon}$ 'sweet/palatable,' j̀doodo 'bitter' and nyagbalaa (a term conflating sour and salty) were used with high consistency.

Focused elicitation yielded many more ideophones relevant to these domains. For example, other ideophones in the texture domain evoke such tactile perceptions as pukupuku 'clumpy (like

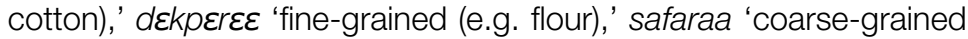
(e.g. sand),' kpد/دkpد/د 'unpleasantly slippery (e.g. muddy road, mudfish).' Other ideophones related to taste and flavor include saaa 'cool sensation (e.g. ginger)' and sùùù 'burning sensation (e.g. pepper)' as well as tactile in-mouth experiences like tsuàìi 'elastic,' màgàdã̀ằ 'hard to swallow,' sikitii 'tough, hard to chew,' and titiritiì 'sticky like a cat's tongue.' Note that in glossing these terms in English, it is often necessary to use paraphrases or source-oriented terms (e.g. fluff, groove, silk, bead, clot, grain), whereas in Siwu they
Ideophone

Other Abstract

Source

Evaluative 
are non-derived, basic terms. Siwu ideophones thus pinpoint very specific perceptions in and of themselves. What uses do people make of such a highly specific sensory vocabulary? To explore the cultural significance of ideophones, we turn to their use in everyday conversations in Siwu.

\section{Ideophones in Everyday Language}

Looking at the use of ideophones in a video corpus of natural conversation in Siwu spanning several hours and over thirty different interactions, the first thing to be noted is their sheer ubiquity. In the transcribed part of the corpus, amounting to over 3,000 utterances, about one in twelve utterances contains an ideophone. Ideophones are used in many everyday situations. Workers squeezing palm fruit fiber to produce palm oil comment on the consistency of the substance (potopots 'mushy') and pride themselves on getting the fiber kerenkeren 'squeaky-clean.' A bystander teases one of them by drawing attention to the sweat gushing off his skin (minomin 'sweaty') and the wiggling of his behind (zigizigi). On another compound, a woman complains about the feel of the squeezing net (gbegbegbe 'stiff'), though the others think that it is rather her own

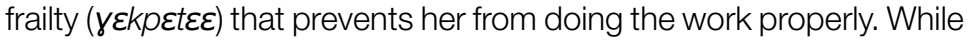
pounding ingredients for gunpowder, a specialist notes that good

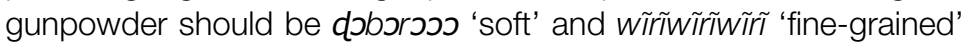
and one of his collaborators points out that fake gunpowder has a dull black color (kpinàkpinà), while the real stuff twinkles gelegelegele. People lingering in the public area provide running commentary on passersby (a young man ambling by gbij่̀ 'sluggishly,' a woman walking upright beautifully $k p \tilde{\varepsilon} g \tilde{\varepsilon} \tilde{\varepsilon})$; sometime later, a farmer stops by to offer some fruit, bringing us back to the scene sketched at the beginning of the article.

Such day-to-day occurrences form the habitat of ideophones in Siwu discursive practice. With these examples in hand we are in a position to appreciate three forms of everyday aesthesis that ideophones afford. First, the use of ideophones is often accompanied by a sense of playfulness. As Fortune noted, "they bring a sense of ease and mirth" (1962: 6), and indeed Siwu speakers clearly delight in their use. Ideophones thus are a source of aesthetic gratification. Secondly, their use during joint activities underlines the aesthetic "disposition to sense acutely" mentioned above. Their precise perceptual meanings make them communicative precision tools, enabling collaborators to communicate and negotiate procedural knowledge relevant to the activities they are engaged

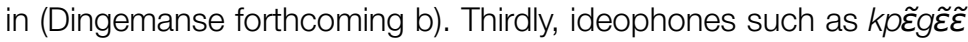
'beautifully upright' and zigizigi 'wiggling the behind' do not just evoke perceptions, they also imply a certain stance and are routinely used to exercise judgments. Here, we see how ideophones performatively elaborate the judgment of taste (Bourdieu 1984) through links between sensory modes and moral codes (Geurts 2002). 


\section{Concluding Remarks}

"Aesthetics is too important to be left in the hand of aesthetes," quips Postrel (2003) in a study of the aesthetics of such everyday objects as drawer pulls and lavatory faucets. This is a welcome change from the almost exclusive focus on the artistic object that has characterized discourse on aesthetics for a long time (Postrel is not alone; see Saito 2007, among others). I want to sketch a parallel movement suggested by ideophones: from the aesthetics of verbal art to the aesthetics of everyday language. Even though the importance of aesthetics has not been lost on students of language (e.g. Jakobson 1960; Mukarovský 1964), here too, the focus has tended to be on the artistic object (i.e. genres and performances of verbal art) as opposed to the aesthetics of patterns of everyday language use. Ideophones remind us that such everyday patterns of language use can be a source of aesthetic pleasure for speakers. As Jdime Kanairo, one of my friends and Siwu teachers, puts it, "Without these words, speech is buàa (bland). You need to pepper it."

Ideophones also highlight the possibility of a collective aesthetic sensibility. As shared, conventionalized signs with socially mediated interpretations, they cultivate certain ways of attending to the perceptual world. In the words of my senior teacher Ruben Owiafe, ideophones "illuminate things" (ikparara ara) so that "people will see and learn" (màanya ne màdi ite). In Mawu society, this "seeing and learning" starts at an early age in the form of an emphasis on sensory modes like gait, balance, disposition, and appearance in child socialization (see Geurts 2002 for a sensitive description of these processes among the nearby Anlo of southern Ghana). Ideophones highlight a concern with the exact qualities of perception. This is why Mawu children may tease the white researcher living in their village by imitating his way of walking and by singing a song mocking his

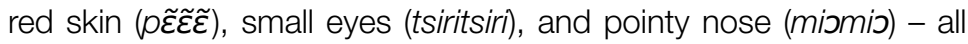
ideophones. It is also why Mawu adults can negotiate knowledge and understanding during joint activities not with cold technical terms, but with vivid sensory language.

As a source of aesthetic gratification and a communicative tool that allows for perhaps unparalleled precision in the linguistic encoding of perceptual qualities, ideophones belie the false dichotomy suggested by Max Müller's ideological declaration of "playthings, not tools." In ideophones, we have an expressive resource that combines sheer playfulness with extraordinary precision. They are playthings and tools.

\section{Acknowledgments}

I thank the Mawu people, especially Jdime Kanairo, Ruben and Ella Owiafe, Rev. A.Y. Wurapa, and Stephen Addae, for teaching me their language. Mì ndo karabra ló! I am grateful to the other members of the Max Planck Institute for Psycholinguistics Categories across 
Language and Cognition project, where these ideas took shape and were written up in considerably more detail in a doctoral dissertation on the meaning and use of ideophones in Siwu.

\section{Notes}

1. Siwu orthography follows the International Phonetic Alphabet relatively closely. The digraphs /dz/ and /ts/ stand for the palatal stops [c] and [j], /ny/ stands for the palatal nasal [ $\mathrm{n}]$, and $/ \mathrm{kp} /$ and $/ \mathrm{gb} / \mathrm{stand}$ for the doubly-articulated labiovelar stops [kp] and $[\vec{g} \vec{b}]$. Grave accents over vowels mark low tone, as à in kànya 'mouth.'

2. A common evaluative response pattern in the smell task involved the antonyms krõkrõ 'smelling good' and nyanyarĩ 'dirty/smelling bad.' These are formally ideophones, but they are coded as evaluative here because their meaning is primarily evaluative, as opposed to the meanings of the ideophones used in the other tasks. Incidentally, that talk about olfaction often contains a strong evaluative component appears to be a cross-linguistically widespread pattern (cf. Classen 1993); this seems to hold even in languages with highly specialized odor vocabularies (cf. Burenhult and Majid, this issue; Tufvesson, this issue).

\section{References}

von Baumgarten, Alexander Gottlieb. 1750. Aesthetica, 2 Vols. Frankfurt an der Oder: Johann Christian Kleyb.

Bourdieu, Pierre. 1984. Distinction: A Social Critique of the Judgement of Taste. Trans. Richard Nice. Cambridge, MA: Harvard University Press.

Classen, Constance. 1993. Worlds of Sense. London: Routledge.

Dingemanse, Mark. 2009. "Ideophones in Unexpected Places." In Peter K. Austin, Oliver Bond, Monik Charette, David Nathan and Peter Sells (eds), Proceedings of Conference on Language Documentation and Linguistic Theory 2, pp. 83-94. London: SOAS.

Dingemanse, Mark. Forthcoming a. "Ezra Pound among the Mawu: Ideophones and Iconicity in Siwu." In Pascal Michelucci, Olga Fischer and Christina Ljungberg (eds), Iconicity in Language and Literature, 10. Amsterdam: John Benjamins (in press).

Dingemanse, Mark. Forthcoming b. "The Meaning and Use of Ideophones in Siwu." Ph.D. dissertation, Radboud University/ Max Planck Institute for Psycholinguistics, Nijmegen.

Evans-Pritchard, E.E. 1962. "Ideophones in Zande." Sudan Notes and Records 34: 143-6.

Fortune, G. 1962. Ideophones in Shona: An Inaugural Lecture Given in the University College of Rhodesia and Nyasaland on 28 April 1961. London: Oxford University Press. 
Geurts, Kathryn Linn. 2002. Culture and the Senses: Bodily Ways of Knowing in an African Community. Berkeley, CA: University of California Press.

Gregor, Mary J. 1983. "Baumgarten's 'Aesthetica.'” The Review of Metaphysics 37(2): 357-85.

Jakobson, Roman. 1960. "Closing Statement: Linguistics and Poetics." In Thomas A. Sebeok (ed.), Style in Language, pp. 350-77. Cambridge, MA: MIT Press.

Majid, Asifa and Levinson, Stephen C. 2007. "Language of Perception: Overview of Field Tasks." In Asifa Majid (ed.), Field Manual, Vol. 10, pp. 8-9. Nijmegen: Max Planck Institute for Psycholinguistics.

Mukarovský, Jan. 1964. "The Esthetics of Language." In Paul L. Garvin (ed.), A Prague School Reader on Esthetics, Literary Structure, and Style, pp. 31-69. Washington, DC: Georgetown University Press.

Müller, F. Max. 1899. The Science of Language: Founded on Lectures Delivered at the Royal Institution in 1861 and 1863, 2nd edn, 2 Vols. London: Longmans, Green, and Co.

Noss, Philip A. 2001. "Ideas, Phones and Gbaya Verbal Art." In F.K. Erhard Voeltz and Christa Kilian-Hatz (eds), Ideophones, pp. 241-55. Amsterdam: John Benjamins.

Nuckolls, Janis B. 1995. "Quechua Texts of Perception." Semiotica 103(1/2): 145-69.

Postrel, Virginia I. 2003. The Substance of Style: How the Rise of Aesthetic Value Is Remaking Commerce, Culture, and Consciousness. New York: HarperCollins.

Saito, Yuriko. 2007. Everyday Aesthetics. Oxford: Oxford University Press.

Sherzer, Joel. 1987. "A Discourse-Centered Approach to Language and Culture." American Anthropologist 89(2): 295-309.

Webster, Anthony K. 2008. "'To Give an Imagination to the Listener': The Neglected Poetics of Navajo Ideophony." Semiotica 171(1/4): 343-65.

Whitehead, J. 1899. Grammar and Dictionary of the Bobangi Language. London: Kegan Paul, Trench, Trübner and Co. 